\title{
THE MUNICH DUST COUNTER - A COSMIC DUST EXPERIMENT ON BOARD OF THE MUSES-A MISSION OF JAPAN
}

E.Igenbergs, A.Hüdepoh1 [1], K.Uesugi, T.Hayashi [2], H.Svedhem [3], H.Iglseder [4], G.Koller [5], A.Glasmachers [6], E.Grün [7], G.Schwehm [3], H.M1zutani, T.Yamamoto, A.Fujimura, N.Ishii, H.Araki [2], K.Yamakoshi [8], K.Nogami [9]

[1] Lehrstuhl für Raumfahrttechnik, Technische Universität Müchen, Richard Wagner Str. 18, 8000 München 2, FRG

[2] Institute of Space and Astronautical Science, J

[3] European Space Research and Technology Centre of ESA, NL

[4] Center for Applied Space Technology and Microgravity, Universität Bremen, FRG

[5] Lehrstuhl für Prozeßrechner, Technische Universität Hünchen, FRG

[6] Hikroelektronik-Zentrum, Ruhr-Universität Bochum, FRG

[7] Max-Planck-Institut für Kernphysik, Heidelberg, FRG

[8] Institute for Cosmic Ray Research, University of Tokyo, $J$

[9] Dep. of Physics, Dokkyo University School of Medicine, J.

ABSTRACT. The Munich Dust Counter (MDC) is a scientific experiment on board of the MUSES-A mission of Japan. It is the result of a cooperation between the Institute of Space and Astronautical Science (ISAS) of Japan and the Chair of Astronautics of the Technische Universität München (TUM) of Germany. The MDC is an impact ionization detector designed to determine mass and velocity of cosmic dust. Here a short overview over the MUSES-A mission is given to show the measurement situation of the MDC experiment. The measurement principle of the instrument together with a discussion of the scientific objectives and the design of the experiment is summarized.

\section{Introduction}

In 1987 ISAS offered TUM the opportunity to fly a scientific experiment on the MUSES-A mission, the 13th scientific satelite developed and launched by ISAS. The MUSES-A mission has been launched on January 24 , 1990, from Kagoshima Space Center, Japan. ISAS and TUM agreed that TUM would develop and bullt a space experiment to measure cosmic dust particles by impact ionization within the specifications and the time frame set by ISAS. The weight of the instrument was limited to $800 \mathrm{~g}$, the power consumption to $2.5 \mathrm{~W}$. This experiment has been named Munich Dust Counter (MDC) and has been delivered to ISAS in September 1989.

45

A.C. Levasseur-Regourd and H. Hasegawa (eds.), Origin and Evolution of Interplanetary Dust, 45-48.

(C) 1991 Kluwer Academic Publishers, Printed in Japan. 
The MUSES-A satellite is a spin stabilized type spacecraft composed of a cylindrical main body, $1.4 \mathrm{~m}$ in diameter and $0.8 \mathrm{~m}$ in height. The MDC is installed on the edge of the instrument platform with an aperture of $12 \times 12 \mathrm{~cm}$. As the spin axis is maintained perpendicular to the ecliptic plane and the spin rate is $20 \mathrm{rpm}$, the MDC therefore scans within $3 \mathrm{sec}$. over $360^{\circ}$ in the ecliptic plane. The field of view of the experiment is about $148^{\circ}$. Details of the mission of MUSES-A, which includes multiple lunar swingby maneuvers, are given by Uesugi et al. (1990).

\section{Scientific Objectives of the Experiment MDC}

The sensitivity and effective sensor area of the MDC are similar to the dust detectors on board of the spacecraft Pioneer 8 , Berg and Richardson (1969), and HEOS-2, Hoffmann et al. (1975). Phenomena to be Investigated in detail will include the interplanetary dust flux, dust in the earth's magnetosphere and magnetotail, and the lunar dust environment.

\section{LDC Measurement Principle}

The MDC experiment measures the electrical charges generated by the impact of small masses on a gold surface. The basic setup of the MDC as shown in fig. 1 consists of a target and two charge collectors which are biased by positive and negative high voltage, separating the impact plasma into positively and negatively charged components. Connected to the charge collectors are charge sensitive amplifiers which convert the input charge into an output voltage.

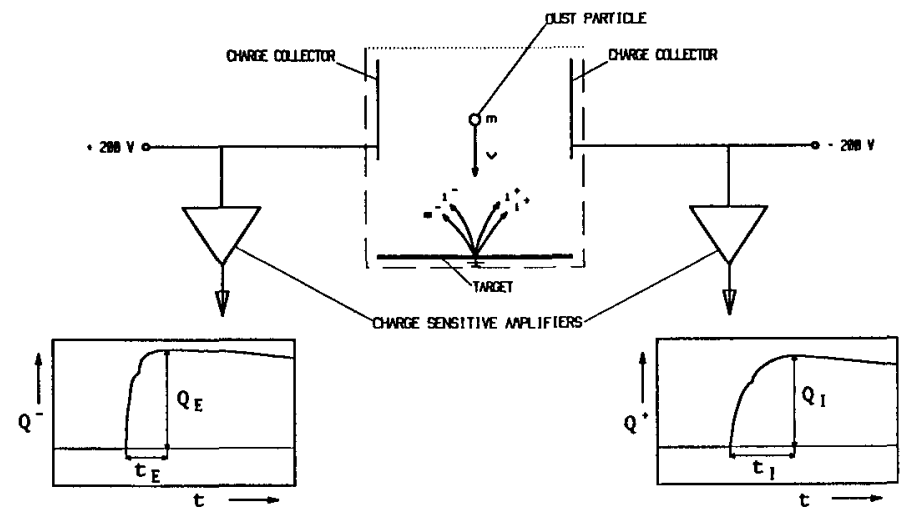

Figure 1. MDC Measurement Principle

For each charge signal amplitude and risetime are evaluated. The mass $m$ and velocity $v$ of the dust particles can be determined by using the following empirical formulae, first found by Frichtenicht and slattery (1962) and adapted for the particular setup by Iglseder (1976):

$$
\mathrm{Q}_{\mathrm{maxK}} / \mathrm{m}=\mathrm{c}_{\mathrm{rK}} \cdot \mathrm{v}_{\mathrm{K}} \quad \text { and } \quad \mathrm{t}_{\mathrm{K}}=\mathrm{c}_{\mathrm{gK}} \cdot \mathrm{v}_{\mathrm{K}} \text {, }
$$


valid for the Ion channel $(K=I)$ and electron channel $(K=E)$ with: $Q_{\text {max }}:$ maximum charge in ion/electron channel

$t \quad$ : rise time of signal in ion/electron channel

The constants $C_{\mathrm{rI}}, \mathrm{C}_{\mathrm{rE}}, \beta_{\mathrm{I}}, \beta_{\mathrm{E}}, \eta_{\mathrm{I}}, \eta_{\mathrm{E}}$ have been calibrated by using the Electrostatic Dust Accelerator of the Max-Planck-Institut für Kernphysik in Heidelberg with particle masses between $10^{-15} \mathrm{~g}$ to $10^{-10} \mathrm{~g}$ and velocities between $2 \mathrm{~km} / \mathrm{s}$ and $58 \mathrm{~km} / \mathrm{s}$, and by using the Plasma Accelerator of TUM with masses between $10^{-1} \mathrm{~g}$ to $10^{-7} \mathrm{~g}$ and velocities up to $20 \mathrm{~km} / \mathrm{s}$. The sensitivity range of the MDC experiment is shown in $\mathrm{fig} .2$. The accuracy of the calculation of the mass is at a factor of 0.4 to 2.5 , the accuracy of the calculation of the velocity is at a factor of 0.7 to 1.5 .

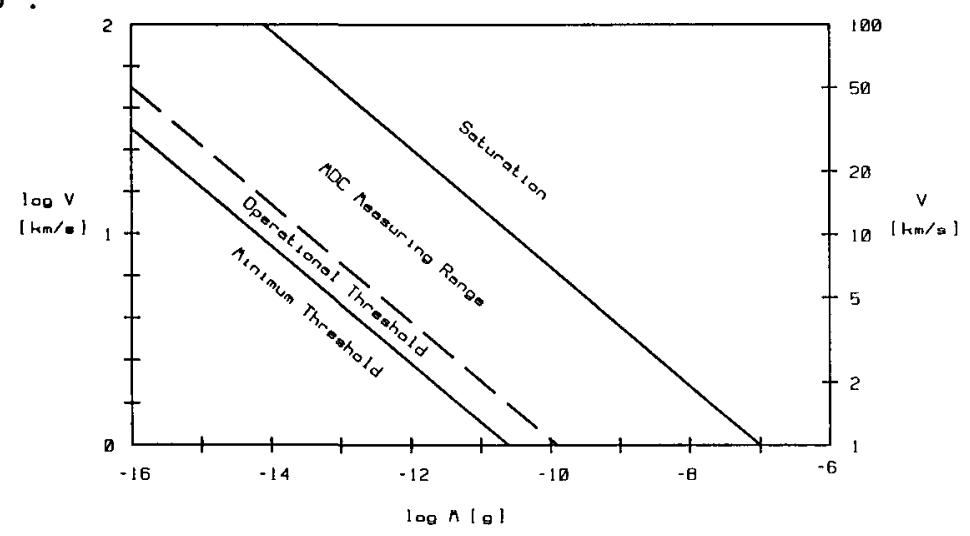

Figure 2. Sensitivity range of the MDC experiment for normal impacts in the target center.

\section{Design of the Experiment MDC}

The actual dimensions of the MDC are $105 \times 110 \times 160 \mathrm{~mm}$, the weight of the flight model is 605 grams. The effective sensor area is $100 \mathrm{~cm}^{2}$. Figure 3 gives a general outline of the MDC design.

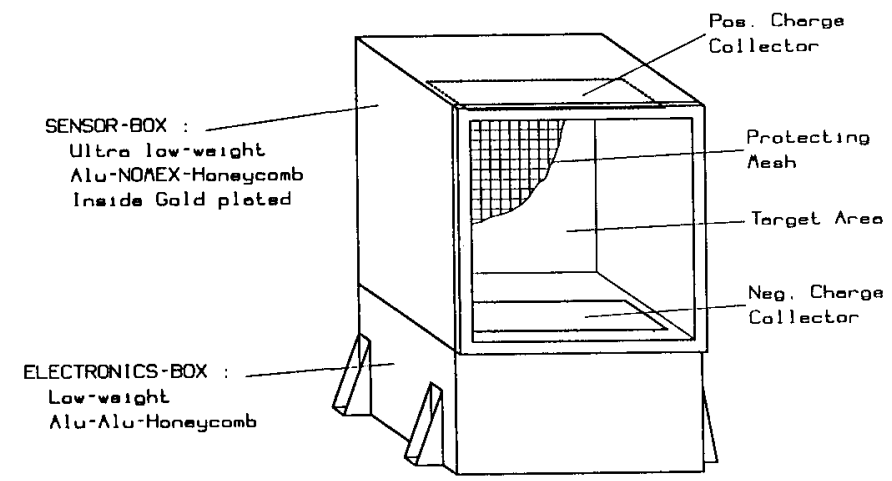

Figure 3. Outline of MDC mechanical design 
The impact charges are converted into a voltage signal by charge sensitive amplifiers with a sensitivity from $5 \cdot 10^{-15} \mathrm{Cb}$ to $5 \cdot 10^{-11} \mathrm{Cb}$. The output of the charge sensitive amplifiers (electron and ion channe1) is digitized and stored in a transient recorder consisting of two 8 bit $A / D$ converters, clocked with $5 \mathrm{MHz}$ each and using a FIFO memory.

A microprocessor system, $80 \mathrm{C} 85 \mathrm{CPU}$ with 2 KByte ROM and 32 KByte RAM, processes measured signals, controls the spacecraft interface and monitors voltages and temperatures. A switching power supply uses $+29 \mathrm{~V}$ input to generate a $\pm 6 \mathrm{~V}$ output for the charge sensitive amplifiers and $\pm 200 \mathrm{~V}$ for the bias voltages of the charge collectors. The power consumption of the MDG flight model is 1.8 Watts.

Generally this design allows to record and store the whole particle impact signals. The amount of impact data is 1 KByte per signal or 512 byte per channel, giving a total measurement time of $100 \mu \mathrm{s}$. Together with the impact data calibration and housekeeping data valid for the time of impact are stored and transmitted down to ground, giving the opportunity to inspect on the ground the real signals measured in space.

\section{Conclusion}

Within a cooperation between the Institute of Space and Astronautical Science of Japan and the Technische Universität München of Germany the scientific experiment Munich Dust Counter has been developed and manufactured within two and a half years from start of the project until integration on the satellite MUSES-A. By measuring dust particles in a high-elliptical earth orbit and in the vicinity of the Moon, valuable information about the mass, velocity and the flight direction of cosmic dust will be obtained. Preliminary results of the operation of the MDC from January to July 1990 are described by Igenbergs et al. (1990).

\section{References}

Berg O.E., Richardson F.F (1969) 'The Pioneer 8 Cosmic Dust Experiment', Rev. Sci. Instrum. 40, 1333-1337.

Friichtenicht J.F., Slattery J.C. (1962) 'Ionization Associated with Hypervelocity Impact', NASA Technical Note D-2091.

Hoffmann H.-J., Fechtig H., Grün E., Kissel J.(1975) 'First Results of the Micrometeoroid Experiment S 215 on the HEOS 2 Satellite', Planet. Space Sci., 23, 215-224.

Igenbergs E. et a1.(1990) 'The Present Status of the Munich Dust Counter Experiment on Board of the HITEN Spacecraft', Proc. of the IAU Coll. No. 126 "Origin and Evolution of Interplanetary Dust", Kyoto.

Iglseder H. (1986) 'Ladungsemission beim Hochgeschwindigkeitseinschlag', Dissertation, Lehrstuhl für Raumfahrttechnik, Technische Universität München.

Uesugi K., Matsuo H., KawaguchI J. HayashI T. (1990) 'Japanese first Double Lunar Swingby Mission HITEN', Proc. of the 41st Congress of the IAF, Dresden. 